\title{
TECNOLOGIAS DA INFORMAÇ̃̃O E COMUNICAC̣̃̃O E QUALIDADE DA EDUCAÇÃO NA PERSPECTIVA DE UMA PROFESSORA DE CIÊNCIAS
}

\author{
Marcia Duarte* \\ Flavia Rezende**
}

RESUMO: Apresentamos um estudo que tem por objetivo compreender os sentidos atribuídos à relação entre a utilização das Tecnologias de Informação e Comunicação (TIC) e a qualidade da educação científica na vOz de uma professora de ciências do ensino fundamental de uma escola com infraestrutura material e pedagógica para a utilização desses meios. Para a análise do discurso, recorremos à teoria das vozes de M. Bakhtin. Percebemos que o uso das TIC é visto como qualidade educacional por proporcionar acesso ao conteúdo científico, embora não represente propostas pedagógicas inovadoras, sendo apenas associado ao aumento da motivação dos alunos. A análise também permitiu compreender que essa relação é conformada, em seu discurso, pelas diferentes realidades educacionais em que as TIC são inseridas.

Palavras-chave: Tecnologias da informação e comunicação, qualidade, Educação em Ciências.

INFORMATION TECHNOLOGY AND QUALITY OF EDUCATION IN THE PERSPECTIVE OF A SCIENCE TEACHER

ABSTRACT: This study aimed to understand the meanings attributed to the relationship between the use of information and communication technology (ICT) and the quality of science education in the voice of a science teacher who works in a school with material and pedagogical structure to incorporate these tools. We used the theory of voices by M. Bakhtin to analyse the discourse. We observed that the use of ICT is seen as educational quality because it provides access to content, and although it does not represent innovating pedagogical proposals it is associated with increased of student motivation. The analysis also showed that this relationship is structured by the different educational realities in which ICT are inserted.

Keywords: Information technology, quality, Science Education. 


\section{INTRODUĈ̣̃O}

Desde a década de 1960, a educação geral e a educação científica, em particular, têm sido vistas como fatores de sustentação e aceleração do desenvolvimento científico-tecnológico do país. Por parte do governo, a aspiração de desenvolver o país tendo a educação como um fator crucial de melhoramento das forças produtivas para atender às novas exigências do mundo do trabalho; por parte da população, o desejo de se beneficiar dos recursos educativos e integrar-se ao novo momento do país, que crescia e se industrializava.

Como as práticas da educação formal, então vigentes, não atendiam às novas demandas produtivas, somado ao status docente que não desfrutava de um estatuto propriamente profissional, imprimiu-se certa dose de cientificismo à prática docente, utilizando-se o discurso científico e as técnicas de ensino para legitimar a institucionalização dos especialistas em educação e profissionalizar o ensino. Dessa forma, generaliza-se na educação um movimento de incorporação de técnicas administrativas, psicológicas e pedagógicas. Nesta pedagogia, dita tecnicista, o centro de ensino não é mais o professor, nem mais o aluno, mas as técnicas (SAVIANI, 1984). A partir delas, reorganiza-se o processo educativo no sentido de torná-lo objetivo e operacional. O ensino passa a burocratizar-se mediante planejamentos, operacionalização de objetivos, instrumentos para medir comportamentos observáveis, mensuráveis e controláveis. Dissemina-se o uso da instrução programada, das máquinas de ensinar, testes de múltipla-escola, tele-ensino e múltiplos recursos audiovisuais. Na década de 80, é lançado o primeiro projeto governamental de disseminação do uso do computador na educação (EDUCOM). Esse projeto visava, além da melhoria da aprendizagem, a familiarização dos estudantes com a informática, tendo em vista o mercado de trabalho.

Saltando das demandas econômicas das décadas de 1960, 70 e 80 para a atual sociedade globalizada marcada pela inserção das TIC, vale perguntar de que forma as atuais demandas redefinem o papel da escola a fim de produzir uma educação de qualidade. A reforma educacional vigente desde o final da década de 1990, ao colocar a centralidade do conhecimento e da tecnologia nos processos de produção e organização da vida social, institui um novo paradigma, em que as competências desejáveis ao pleno desenvolvimento humano aproximam-se das competências necessárias à inserção no processo produtivo. Admitindo-se tal correspondência entre as competências exigidas para o exercício da cidadania e para as atividades produtivas, recoloca-se o papel da educação como elemento de desenvolvimento econômico e social.

Se a ciência e a técnica sustentaram as premissas da pedagogia tecnicista visando à melhoria da qualidade da educação, a fim de atender às demandas do mundo do trabalho, a inserção das TIC na educação, pelas políticas educacionais vigentes, traz a renovação desse discurso e desencadeia outros discursos. Esses discursos compõem o que Felinto (2005) denominou de "imaginário tecnológico", ou seja, "conjunto de representações sociais e fantasias compartilhadas que 
informam nossas concepções sobre as tecnologias" (p. 7). Uma das principais representações concebe as TIC como rendição dos problemas educacionais, capazes de transformar, de forma mágica, o processo tradicional de ensino em verdadeiras aulas-espetáculo e, desse modo, combater o desinteresse dos alunos frente aos conteúdos. Assim, a qualidade da educação seria alcançada pelo "emprego de recursos tecnológicos que promoveriam a atratividade dos ensinamentos oferecidos aos alunos ou por eles aprendidos sem uma interferência significativa do(a) professor(a)" (MOREIRA e KRAMER, 2007, p. 1038).

Como exemplo da equiparação entre uso das TIC e qualidade da educação, podemos recorrer aos programas contemplados pelo PDE (BRASIL, 2007), como por exemplo, E-ProInfo, Formação pela Escola, Mídias na Educação, ProInfo Integrado, Pró-Letramento, Pro-Licenciatura, Sistema Universidade Aberta do Brasil e Banco Internacional de Objetos Educacionais. Assim, do ponto de vista das políticas educacionais, é possível observar a construção de um discurso que relaciona linearmente o uso da tecnologia à qualidade da educação. A partir de sua implementação, esperava-se que essa relação fosse assimilada por todo o sistema educacional.

A apropriação desse discurso pelo meio acadêmico na área de Educação e em Educação em Ciências, especificamente, tem gerado diferentes reações. $\mathrm{Na}$ educação científica, os autores em geral defendem as vantagens das TIC como novos recursos didáticos que atualizam e facilitam o ensino, ou que motivam ou contribuem para o processo de aprendizagem de Ciências (veja, por exemplo, GIORDAN, 2005; TONIATO ET AL, 2006; SERRA E ARROIO, 2007). Nesses trabalhos, os recursos computacionais são utilizados para a pesquisa de temas pelos alunos, elaboração de gráficos, planilhas, obtenção de dados em experimentos, visualização de imagens e simulações com a finalidade de motivar ou "modernizar" a aula. Na área de Educação, em contrapartida, encontramos autores que problematizam a inserção das TIC na Educação (por exemplo, PRET'TO, 2001; BARRETO, 2009), chamando atenção para a necessária recontextualização desses artefatos, uma vez que são criados em um dado momento histórico e com propósitos específicos.

Entendendo que a apropriação dos discursos envolve um processo de diálogo com intenções e valores que acabam por construir novos sentidos, este estudo problematiza a relação entre o uso das TIC e a qualidade da educação, por meio da investigação de sua apropriação por uma professora de Ciências de uma escola com infraestrutura material e pedagógica para a inserção da tecnologia na educação. Pelas condições favoráveis dessa escola, pela aproximação social entre ciência e tecnologia e pela associação das TIC à qualidade da educação na pesquisa em educação em ciências, pressupomos que a apropriação desse discurso pela professora siga este mesmo sentido. A intenção desse arranjo foi amplificar qualquer variação que viesse a ocorrer em relação a essa hipótese. 


\section{FUNDAMENTAC̣ÃO TEÓRICO-METODOLÓGICA}

Nosso referencial teórico-metodológico entende a linguagem como ato social situado histórico-socialmente e que, portanto, não existe fora de um contexto social, já que cada sujeito falante tem um horizonte social e se dirige para um interlocutor real ou suposto, para um auditório social bem definido (BAKHTIN, 2004).

Como princípios constitutivos da filosofia da linguagem de Bakhtin, destacamos os de alteridade, dialogismo e direcionalidade. O primeiro pressupõe a existência do outro como uma entidade implícita na produção de qualquer enunciado e na relação com esse outro é construído o sentido. Para o autor, "a alteridade define o ser humano, pois o outro é imprescindível para sua concepção: é impossível pensar no homem fora das relações que o ligam ao outro" (BAKHTIN, citado por BRAIT, 2005, p. 28).

O conceito de dialogia amplia a problemática da alteridade na medida em que concebe a linguagem como mecanismo de diálogo entre interlocutores e entre discursos. O primeiro trata da interação verbal entre sujeitos e sobre a intersubjetividade. O segundo, diálogo entre discursos, pressupõe a relação com outros discursos, o que leva o autor a conceber o enunciado, enquanto unidade da comunicação verbal, como um tecido constituído por um conjunto de vozes. Ou seja, como nenhum falante é o Adão bíblico, para Bakhtin (2003), qualquer enunciado, ao se pôr em contato com outras vozes, "se torna inevitavelmente um palco de encontro com opiniões de interlocutores imediatos ou com pontos de vista, visões de mundo, correntes, teorias, etc." (p. 300).

O processo de enunciação para Bakhtin é a produção de enunciados, entendidos como expressão e produto da interação social, verdadeiras unidades de análise e da comunicação verbal, que só podem existir se produzidos por uma voz. O conceito de voz em Bakhtin não se refere a sinais auditivo-vocais, mas se aplica tanto à comunicação oral como à escrita, além de envolver questões mais amplas da perspectiva do sujeito falante, seu horizonte conceitual, sua intenção e sua visão de mundo. Desse modo, interação verbal refere-se, além do diálogo entre dois falantes, à interanimação de vozes contidas no enunciado. Para ele, toda enunciação é tecida por um conjunto de vozes que dialogam entre si, como um elo de uma cadeia discursiva que não pode ser separado dos elos precedentes, nem tampouco daqueles que geram nele "atitudes responsivas diretas e ressonâncias dialógicas" (BAKHTIN, 2003, p. 300).

O enunciado enquanto unidade real de análise da comunicação discursiva possui peculiaridades estruturais, como os limites de cada enunciado, a conclusividade, as relações específicas entre enunciados e a relação do enunciado com o próprio autor e com outros participantes da comunicação. Nesse artigo, estabelecemos como foco de interesse essas relações dialógicas como marcas discursivas que nos possibilitarão identificar nas vozes dos professores entrevistados, o diálogo que estes estabelecem com outras vozes. Para isso, lançamos mão dos conceitos de compreensão, apropriação e ventrilocução, discursos citado (ou de outrem), 
discurso indireto como eixos balizadores para a análise do discurso.

A compreensão da linguagem é uma reação ativa a propósito do que é dito, porque "a cada palavra da enunciação que estamos em processo de compreender, fazemos corresponder uma série de palavras nossas, formando uma réplica" (BAKHTIN, 2004, p. 132). No entanto, não se pode interpretar a compreensão apenas como concordância, embora ela seja "uma das formas mais importantes de relações dialógicas” (BAKHTIN, 2003, p. 331), nem entender as relações dialógicas em termos simplificados e unilaterais, reduzindo-as a uma contradição, luta, discussão, desacordo. Como afirma Bakhtin (2004), "toda enunciação efetiva, seja qual for a sua forma, contém sempre, com maior ou menor nitidez, a indicação de um acordo ou de um desacordo com alguma coisa. É a pluralidade de acentos avaliativos que dá vida à palavra" (p. 107).

Para Bakhtin (2003), só pode haver significado quando duas ou mais vozes entram em contato. Uma das formas de tomar uma posição com relação ao discurso do outro é por meio da apropriação, que é a ação de povoar as palavras do outro com intenção e expressão próprias, e torná-las palavras próprias (BAKHTIN, 1994, p. 293). Apropriar-se do discurso é, em parte, tornar suas, as palavras do outro, lhes acrescentando intenção semântica e expressividade próprias, dando voz a sua manifestação discursiva e promovendo sua reconstrução.

A compreensão e apropriação podem ser entendidas como movimentos de apreensão ativa da enunciação de outrem, que têm sua expressão no discurso interior e, é a partir deste que o falante se orienta. Já o discurso de outrem, ou citado, é visto pelo autor do enunciado como a enunciação de "outra pessoa, completamente independente na origem, dotada de uma construção completa, e situada fora do contexto narrativo" (BAKHTIN, 2004, p.144). O discurso indireto integra ativamente o discurso de outrem como uma tomada de posição com conteúdo semântico preciso por parte do falante, que além de apreender e transmitir o objeto do discurso enquanto expressão, pode trazer ainda o próprio falante.

Quando nos apropriamos do discurso alheio, o mesmo está sujeito a certas mudanças semânticas na medida em que acrescentamos nosso acento. O contexto que envolve as palavras do outro, responsável por seus antecedentes dialógicos, entra no nosso discurso não como uma ligação mecânica, mas em união química (BAKHTIN, 1994), ou seja, nos níveis semânticos e emocionalmente expressivos.

A depender do contexto e da função de um discurso, podemos pensar que em todo enunciado as funções dialógica e unívoca se encontram em uma espécie de tensão dinâmica. Como nos adverte Wertsch (1993), é preciso escutar sempre o que um falante diz, entendendo que o que é dito não gera mecanicamente uma interpretação exclusiva. "A questão da tensão dinâmica está vinculada aos contextos socioculturais" (p. 100). Por essa razão, como o objetivo deste estudo é compreender os sentidos atribuídos à relação entre as TIC e a qualidade da educação em Ciências na voz de uma professora, escolhemos analisar as relações dialógicas presentes no seu discurso como indicadores de tensões, assumidas como relações de força que se estabelecem no contexto enunciativo do autor e entre este 
e o contexto dos discursos de outros, como possíveis recontextualizações de discursos alheios, manifestadas sob forma de palavras próprias ou ainda submetidas às amarras do discurso citado. Para isso, procuramos nos orientar pelas seguintes questões investigativas: (i) a relação das TIC com a qualidade da Educação em Ciências está presente na voz da professora? Quais seus possíveis sentidos? (ii) Quais as vozes de outrem que dialogam com a voz da professora? (iii) Como essas vozes se manifestam nas relações dialógicas do seu discurso e conformam a construção da relação investigada?

\section{METODOLOGIA}

A primeira etapa metodológica consistiu na realização de um grupo focal com nove professores de Ciências e Matemática do ensino médio de escolas públicas e privadas, com o objetivo de extrair indicadores temáticos relacionados à qualidade da Educação, a fim de subsidiar a construção do roteiro de entrevista a ser aplicado na segunda etapa do estudo. O critério inicial da análise foi selecionar os episódios ${ }^{1}$ que tinham como conteúdo temático as TIC e a qualidade da educação.

A partir dessa etapa, construímos um roteiro de entrevista semi-estruturada, a ser aplicado a professores de ciências de uma escola que tivesse tradição na área de informática educativa e correspondente infraestrutura disponível para sua inserção, o que foi considerado contexto ideal para a apropriação do uso das TIC como critério de qualidade, como pretendido pelas políticas educacionais. Além de laboratórios de informática, essa escola possui uma equipe de informática educativa disponível para elaboração de projetos educacionais que envolvam as TIC, em parceria com os professores.

Elegemos o estudo de caso como metodologia empírica, por tratar-se de uma pesquisa que pretende aprofundar o conhecimento da realidade educacional específica de um colégio público federal considerado de alto padrão educacional, situado na cidade do Rio de Janeiro, que atende a uma clientela de classe média e classe média baixa. Segundo Merrian (citado por ANDRÉ, 2005), o estudo de caso qualitativo atende a quatro características essenciais: particularidade, descrição, heurística e indução. Nesse caso, a particularidade refere-se a uma situação particular, ou seja, compreender os sentidos atribuídos à relação entre as TIC e a qualidade da educação em Ciências, na voz de uma professora de ciências do colégio investigado. A descrição significa o detalhamento da situação, o que na análise discursiva com base em Bakhtin é a etapa inicial. A heurística amplia a compreensão do leitor sobre o fenômeno estudado, podendo "revelar a descoberta de novos significados, estender a experiência do leitor ou confirmar o já conhecido" (citado por ANDRÉ, 2005, p. 18). E a indução significa que, em sua maioria, os estudos de caso se baseiam na lógica indutiva. Apesar de esse tipo de método investigativo limitar a generalização dos resultados, em alguns casos, por indução e considerando a realidade próxima à situação pesquisada, podemos transferir os resultados 
para outras situações de investigação.

Com o estudo deste caso, pretendemos refinar as perspectivas de professores das Ciências Naturais em relação ao uso das TIC e à qualidade da educação obtidas anteriormente (REZENDE ET AL., 2011), construídas no diálogo com outros discursos e não apenas com base na falta de cultura tecnológica ou de infraestrutura material da escola, justificativas frequentemente usadas no estudo anterior para não utilização.

Neste artigo, apresentamos a análise da entrevista realizada com Marina, professora do colégio federal já citado, no qual ministra aulas de Ciências no ensino fundamental e Biologia no ensino médio e de um colégio privado que atende a um público de classe alta.

Considerando a linguagem como processo e produto da atividade humana e, portanto, como prática social, política e ideológica (BAKTHIN, 2003), é imprescindível o entendimento do cenário enunciativo, que não pode ser dissociado da situação imediata que o criou nem do contexto social mais amplo. Desse modo, na análise da entrevista, procuramos seguir a "ordem metodológica" indicada por Bakhtin, descrevendo inicialmente as condições concretas da situação em que os enunciados da professora foram produzidos. Para Bakhtin (2004), a situação é composta por elementos extra-verbais que definem o tempo e o espaço do evento discursivo, o tema ou conteúdo semântico e a posição dos interlocutores (auditório social). A situação "se integra ao enunciado como uma parte constitutiva essencial da estrutura de sua significação" (VOLOSHINOV, 1976). Segundo Miotello (2006), a análise do "contexto extra-verbal" articula o verbal e o não-verbal, o dito e o não-dito, o posto e o pressuposto, o entendido e o subentendido.

Para somar à análise discursiva de matriz histórico-social, adotamos a análise microgenética de cunho sociocultural, que prioriza a análise de processos. A análise microgenética pode ser caracterizada como uma forma de conhecer que é orientada para minúcias e ocorrências residuais, como indícios, pistas, signos de aspectos relevantes de um processo em curso; que elege episódios típicos e atípicos, os quais permitem interpretar o fenômeno de interesse; que é centrada na intersubjetividade e no funcionamento enunciativo-discursivo dos sujeitos (SILVA e SCHNETZLER, 2009).

$\mathrm{Na}$ etapa de definição do corpus de análise, procuramos identificar os momentos nos quais a professora evidencia suas perspectivas de qualidade do ensino de ciências e das TIC, em ocorrências ao longo de sua interação discursiva com a pesquisadora. Como a situação de entrevista produz respostas dos sujeitos entrevistados a perguntas dirigidas a eles, os enunciados são naturalmente delimitados pela alternância entre falantes. Tomamos como enunciados as respostas da professora a cada pergunta, entendendo-as como contra-palavras que podem complementar, contradizer, elucidar ou gerar novos sentidos. E em cada enunciado, destacamos episódios que evidenciam suas perspectivas sobre o objeto investigado.

A partir das questões de estudo, tratamos as enunciações da professora como um concerto polifônico, onde várias vozes se colocam em contato. Desse 
modo, visamos identificar as vozes que se deixam ouvir no texto, em que lugares é possível ouvi-las e quais são as vozes ausentes. Para isso, destacamos, nos enunciados, episódios em que aparecem menções a aspectos da sua prática pedagógica, relatos de experiência, crítica ou acentos avaliativos, comparações, elementos de reflexão, concordâncias ou desacordos, a partir de relações entre esses textos e seus contextos de produção, paráfrases, metáforas ou citação explícita ou indireta de algum texto, autor e outras referências. Esses episódios foram numerados para facilitar a localização dos aspectos analisados na situação enunciativa. Nesse sentido, ainda que não aparecesse a palavra qualidade nas falas dos professores, buscamos identificar a posição valorativa da professora frente às TIC e sua relação com a qualidade da Educação em Ciências.

\section{A VOZ DE MARINA}

A professora fala a partir dos seus 30 anos de experiência no magistério público e privado e como mestre em Educação. Dirige suas respostas para a pesquisadora, professora de Informática Educativa do colégio público em que Marina atua. Embora nosso interesse estivesse voltado para a realidade dessa escola, percebemos que em alguns momentos Marina alterna sua fala referindo-se também à outra escola em que atua.

O objetivo da pesquisa foi apresentado à professora, assim como nosso compromisso em apresentar os dados preservando sua identificação. Como informações precedentes, sabemos que as atividades realizadas no laboratório de informática em parceria com a equipe de Ciências são planejadas pela coordenadora de Ciências e recomendadas aos demais professores como atividades extras para somarem à nota da prova. Sendo assim, o sentido valorativo dessas atividades varia de acordo com o professor, o que faz com que alguns não considerem as atividades na avaliação trimestral.

Partimos da premissa de que Marina, por ser professora do colégio há muitos anos, conhece a dinâmica de utilização do laboratório de informática, aberto para uso dos alunos fora dos horários em que não há aulas previstas ou para uso dos professores, independentemente das aulas de informática educativa.

Destacamos o seguinte episódio de sua resposta à questão relativa à sua prática pedagógica:

1. "Eu normalmente obedeço o programa. Eu obedeço o que as pessoas que junto comigo tão trabalhando naquela série, naquela escola, prá ver exatamente... um ponto comum, uma linha mestra comum. Então eu sigo os padrões, sempre me voltando para o nível de cada um, mas sempre exigindo deles mais um pouquinho do que eles podem. Porque eu acho que essa meninada hoje está cada vez mais ligada, ela pode cada vez mais, ela tem mais recursos (ênfase), então a gente pode exigir mais. [...] eu sigo muito a parte teórica do livro abordado, procuro trazer novidades em termos de assuntos que estejam correndo algum paralelo na mídia [...] e assim a gente vai levando e graças a Deus tem sido tudo muito bem". 
Para falar do conteúdo da disciplina de Ciências, sua organização e suas prioridades, Marina recorre a outras vozes como a do currículo, das pessoas que trabalham com ela, dos padrões, da linha mestra, da parte teórica do livro. Essas vozes são tomadas como palavras de autoridade, que conformam sua prática de ensino. Sua voz própria se pronuncia ao afirmar que, apesar de estar atenta "para o nível de cada um, exige sempre um pouquinho mais do que eles podem".

Encontramos nesse episódio uma pista de que a professora parte de uma pressuposição sobre os alunos ('meninada'). Tomamos o uso das palavras 'ligada' e 'recursos' como indício de referir-se ao acesso dos alunos às TIC. Ela parte dessa pressuposição para afirmar que, por estar mais ligada e ter mais recursos, 'a gente pode exigir mais'. Entendemos tratar-se de um discurso indireto em que se percebe uma dupla voz: a da professora que relata e a voz de quem é relatado (a gente), entendido como o coletivo de professores onde a professora parece se incluir.

Ao justificar sua atitude, alegando que hoje os alunos dispõem de mais recursos, Marina parece estabelecer uma relação positiva entre esses recursos e a aprendizagem, que possibilitariam aos alunos o acesso às informações, o que lhes permitiria obter mais base para que ela possa "exigir mais". Observamos assim, que a pressuposição da professora corresponde à condição para que ela possa exigir mais dos alunos. Desse modo, ela atribui às TIC o papel de incrementar a quantidade de informações a serem transmitidas como conteúdo disciplinar para o aluno e potencializar, assim, o paradigma de um ensino tradicional. Essa visão dialoga com o projeto político pedagógico dessa escola (ao qual tivemos acesso), que se considera "novo no sentido de incorporar o acervo de conhecimentos que a ciência, a tecnologia, e as ciências humanas e comportamentais colocaram modernamente à disposição da Educação; velho no aspecto de não abdicar da cultura humanística de sua origem, de não abrir mão da densidade e da profundidade na transmissão de conhecimentos..." Ou seja, os recursos, que presumimos tratarem-se das TIC, passam de objetos a sujeitos de um processo, se entendermos que são eles que fazem com que a professora exija mais dos alunos. Nesse sentido, a voz daqueles que não estão "ligados" ou não têm esses recursos fica silenciada, ratificando o discurso hegemônico de submissão inevitável à nova ordem na qual as TIC protagonizam importante papel.

No final do seu enunciado, Marina traz a expressão "graças a Deus", que retrata crença religiosa, destoando da linguagem social da Ciência, gênero discursivo próprio de um professor de Ciências. Entendemos que ela se utiliza desse episódio atípico para atribuir qualidade à sua prática docente.

2. "Eu normalmente uso o que a escola pode me oferecer. E quando a escola não pode me oferecer muita coisa, às vezes eu trago painéis, ou às vezes eu crio jogos pra fazer com eles, ou às vezes eu trago um material experimental que eu faço, na maioria das vezes, demonstrativo. Mas quando a escola oferece recursos, eu procuro utilizar esses recursos. Até aqui, tem a informática que eu não tenho utilizado, então, a informática...mas, até porque eu acho que o laboratório coitado, está muito sobrecarregado de muitas matérias, mas eu sei que outras séries usam e fica muito interessante o trabalho; e já estou usando a sala de ciências que tem uma mídia boa, televisão, vídeo próprio e tal. Então a gente já vai, é.. 
explorando mais e eles adoram sair do contexto, do contexto de sala de aula. Eu às vezes gosto de sair pra ir a algum lugar..."

Inferimos que a professora considera que os recursos por ela citados são bons para mudar o dia-a-dia da sala de aula, na medida em que a diversificação das estratégias de ensino desperta o interesse dos alunos e pode implicar melhoria do processo ensino-aprendizagem. A melhoria da qualidade do ensino poderia se dar, assim, pela via da variedade dos recursos utilizados para aumento da motivação.

Ela afirma fazer uso dos recursos que a escola tem para lhe oferecer. Considerando-se que a escola investigada possui laboratório de informática e sala de ciências equipada com recursos específicos da disciplina e audiovisuais, tal afirmação nos fornece indícios de que toda essa infraestrutura poderia ser utilizada pela professora. Entretanto, talvez por ser a pesquisadora também professora de informática educativa, Marina tenha tido necessidade de justificar que, apesar de usar outros recursos, não faz uso do laboratório de informática por compreender que ele é muito demandado por outras disciplinas.

Entendemos que essa negação revela uma contradição com sua própria voz. Entretanto, a professora modaliza essa contradição em dois momentos: ao usar o advérbio 'normalmente' e, o segundo, ao usar o verbo procurar ("procuro utilizar"), o que nos permite supor, no primeiro trecho, que há momentos em que ela não utiliza o que a escola oferece, como no caso da informática. E no segundo momento, ela intenciona utilizar os recursos, o que difere de afirmar que utiliza. Para justificar o motivo pelo qual não utiliza os recursos da informática, levando em conta seu destinatário real (a entrevistadora é professora de informática educativa da mesma escola), ela pressupõe que o laboratório ('coitado') é muito solicitado por outras matérias (sublinhado). Em sua justificativa, observamos duas marcas de dialogicidade: a pressuposição e a ironia. Na pressuposição, a locutora da enunciação está tomando como tácito que o laboratório de informática é muito demandado pelas outras matérias (o que não é verdadeiro). Nesse caso, podemos entender que a pressuposição tem intenção manipulativa, para amenizar o fato da professora não fazer uso e ter que admitir isso para a entrevistadora. Ela ainda lança mão da ironia para reforçar sua justificativa.

Reelaboramos mais objetivamente a pergunta para conhecer o que pensa a professora sobre a relação entre as atividades no laboratório de informática da escola e a melhoria da aprendizagem dos alunos.

3. “... eu acho que sempre é algo diferente, e o que é diferente motiva. Eu acho também o seguinte: esse sistema de três pontos em atividade, seis prá sete pontos na prova, eu não sei até que ponto favorece ou não o resultado dos alunos, mas a verdade é que tais atividades pequenininhas a gente tem chance de conseguir deles melhores notas, mais motivação, porque não é uma PROOVAAA. É uma coisinha que vale um ponto aqui... Então eu acho sim, que ela [a coordenadora de ciências] tem razão, estes trabalhos contribuem muito pra esse resultado de aprovação". 
A professora reforça a relação já estabelecida por ela entre a diversificação do cotidiano da sala de aula e a motivação dos alunos, assim como fez em relação à sala de ciências e às saídas com os alunos. Em seguida, considera todas essas atividades “pequenininhas" porque irão somar, no máximo, três pontos à nota da prova.

Embora a pergunta tenha sido focada nas atividades realizadas com a informática educativa, a professora generaliza a resposta. Apesar de receber o "produto final" dessas atividades feitas na informática para avaliar, ao colocar essas atividades junto com outras em um mesmo bloco, a professora deixa transparecer o desconhecimento do processo de realização dessas atividades realizadas na informática educativa. Sua concepção sobre as TIC na educação pode ser, enfim, resumida a "uma coisinha", uma "atividade pequenininha" frente à atividade em sala de aula. Esse sentido atribuído pela professora fica claro quando compara a atividade à "PROOOOOVA", chamando atenção para a diferença de seu valor em relação à real avaliação de aprendizagem. As qualificações das TIC no diminutivo, assim como a entonação empregada ao pronunciar a palavra "prova" nos dão indícios do seu acento valorativo para essas atividades. Segundo ela, essa característica seria justamente o que agradaria aos alunos, por não representar o sistema de cobrança comum à escola. Desse modo, a professora admite que essas atividades contribuem para a aprovação do aluno, omitindo outros aspectos significativos, que poderiam, de fato, contribuir para a qualidade da aprendizagem.

Sobre o papel da escola frente à avalanche tecnológica, Marina respondeu:

4. "Ah... a escola, ela tem que tá sempre muito ligada porque é onde os alunos têm o maior tempo de vida na verdade. Eles passam a maior parte da vida deles em função da escola [...] eu acho que ela tem que tá muito ligada em tudo, e tem que procurar atender dentro da sua realidade, dentro do possível, as demandas que estas tecnologias que tão aí, tão propondo.”

Quando afirma que a escola "tem que tá sempre muito ligada [...] e tem que procurar atender... dentro do possível as demandas que estas tecnologias que tão aí, tão propondo", ela parece se apropriar do discurso implícito do paradigma tecnoinformacional que legitima a noção de sociedade da informação, reforçado por interesses de diversas esferas, como a econômica, científica, política e cultural (MATTELART, 2006). Ou seja, com a expressão "tem que" a professora admite a incorporação das TIC como obrigação da escola de aderir a uma fetichização tecnológica que entende a técnica e/ou as tecnologias como "rei e senhor de todas as instâncias da vida social, em finalidade última de todos os esforços humanos" (FELINTO, 2005, p. 131). Sua fala se alinha com os Parâmetros Curriculares Nacionais (PCN), que estabelecem que, para a escola "contribuir para a formação de indivíduos que possam exercer plenamente sua cidadania, deve estar aberta e incorporar novos hábitos, comportamentos, percepções e demandas" (BRASIL, 1998, p. 138). O sentido da palavra "demandas", presente tanto no enunciado da professora quanto no texto dos PCN, aproxima-se do entendimento de que cabe 
à escola atender as exigências da sociedade e do mercado, cada vez mais subordinados às tecnologias. Nesse sentido, a professora parece afirmar que a escola "tem que" garantir competências requeridas por essa sociedade globalizada, onde as TIC assumem importante papel.

Quando indagada sobre o papel das TIC no ensino de Ciências e sua utilização para ensinar, ela reforça os sentidos que atribuiu às TIC em questões anteriores.

5. "Na escola, eu acho que ela tem todas as chances, porque é uma área que desperta muita curiosidade nos alunos e as TIC podem exatamente canalizar e atender, direcionar essa busca de conhecimentos, essa busca de novidades".

6. "Bom, normalmente eu costumo utilizar para preparar, para digitalizar toda essa parte de Word, para preparar as fichas e preparar jogos ou enfim, entro muito em busca de informações de conteúdo via internet. É... eu brinco com os meninos que tô tendo aula de PowerPoint é...que preciso aprender PowerPoint; a essas alturas do campeonato, eu ainda não sei, mas é uma tecnologia que eu sei que é muito fácil, e é muito legal também quando a gente usa e tem problema, e aí tem sempre um na sala que sabe mais e a gente tá aprendendo com eles, e eu acho isso fantástico, muito legal".

No primeiro episódio, a professora identifica uma relação direta entre a ciência e as possibilidades de acesso a informações e ao conhecimento científico oferecidas pelas TIC.

Quando traz o relato de ocorrências do seu uso cotidiano dessas ferramentas, percebemos um sentido restrito de utilização pedagógica das TIC. Embora ela utilize alguns aplicativos de texto e apresentação no preparo ou na exposição de suas aulas, não há nenhuma pista de que essa utilização tenha qualquer impacto de fato transformador da sua prática pedagógica. Por outro lado, ela parece avaliar positivamente o fato de não dominar completamente o uso da TIC, por permitir que a ordem do discurso pedagógico seja invertida.

$\mathrm{Na}$ sequência, solicitamos que a professora comentasse sobre o fato de os alunos, hoje em dia, demonstrarem maior domínio no manuseio dos recursos tecnológicos e, assim, interagirem com o professor, invertendo a ordem do discurso pedagógico:

7. "Ontem um aluno me chamou prá me mostrar um Ipad que ele ganhou do pai. Ele foi me buscar na sala dos professores prá me mostrar: Profa, olha aqui, quero te mostrar esse programa aqui da tabela periódica, tal e... Ficou lá me mostrando todos os programas e eu fiquei encantada com...eu já tinha né...já conhecia...é...não tenho esse brinquedinho ainda, não tenho, e ele... eu achei fantástico o fato dele vir me mostrar. Ele disse: Não, o que você quiser no seu computador, o que precisar eu posso te ensinar. Porque eu sei que ele é muito fera. E eu posso te ensinar, posso instalar pra você os programas e tal. E eu fiquei encantada com isso, e eu acho que a gente é isso aí, a gente tem que trocar, não tem idade não".

No episódio acima, notamos que ela responde a partir de outro lugar social, reportando-se à outra realidade sociocultural que é a da escola particular de alto padrão. Em seu discurso, há a voz do aluno entremeada com a sua própria 
voz. Por ser o texto a transcrição de uma conversa, as marcas de intertextualidade na superfície do texto são percebidas pelo conteúdo semântico e pelo tom expressivo empregado. Ela não toma as palavras do outro como suas, e sim as ventrilocuta, expressando um tom valorativo em relação à possibilidade de aprender com os alunos. Do ponto de vista pedagógico, essa inversão do papel do professor quebra o paradigma do ensino tradicional e aproxima os agentes do processo educativo - professor e aluno, tornando o ensino um processo de interação de mão dupla e, portanto, mais enriquecedor para ambas as partes.

Ao pontuar que as TIC disponibilizam outras fontes de informação, perguntamos o que isso muda na relação ensino-aprendizagem.

8. "Eu acho que muda muito, muda muito, porque o que está no livro é aquela coisa quadrada, é a coisa estigmatizada que foi escrita há algum tempo atrás, e ciência como qualquer outra área de conhecimento, é dinâmico, está mudando, e com esses mecanismos aí o que você aprendeu agora daqui a uma hora já passou, então você tem que estar sempre nessa dinâmica toda, então realmente eu acho que só vem a acrescentar. Agora eu acho que o livro, o livro ainda é uma referência, eu não descarto absolutamente. Eu acho que o livro é uma referência, existem coisas que são básicas, que são fundamentais e que estão registradas ali e que eles precisam ter. Nem todos ainda (ênfase) têm acesso às TIC, nem todos têm, nem sempre as escolas podem oferecer esse tipo de recurso. Eu acho que o livro é fundamental sim, [...] é justamente esse suporte no dia a dia. [...] é muito bom a gente saber que a gente pode contar com a informação assim na hora, o que está acontecendo na hora, e você daquilo que está acontecendo na hora você pode pegar um gancho e aplicar naquele conteúdo que você esta desenvolvendo, é muito bom...sem dúvida".

A professora concorda que o acesso a outras fontes de informação disponibilizadas pelas TIC "muda muito" a relação ensino-aprendizagem. Ela justifica sua resposta primeiramente fazendo uma crítica ao livro didático como uma fonte de saber "quadrada, estigmatizada, que foi escrita há algum tempo atrás", e que por isso não acompanha a dinâmica da evolução do conhecimento. Em contrapartida, ela valoriza as TIC pela possibilidade de atualização das informações, o que permite ao professor ter uma prática pedagógica atualizada, trazer fatos ou situações do cotidiano como contextualização do conteúdo a ser ensinado.

Após tecer a crítica ao livro didático, observamos na oração "e que eles precisam ter" e na ênfase dada ao advérbio "ainda", sinais de que ela valoriza sua utilização como um repositório de informações básicas, fundamentais. Nessa tensão de aparente contradição, sua voz parece afinar-se com uma prática pedagógica tradicional, conteudista, que se apóia no livro didático como recurso fundamental. Nesse contexto, a tecnologia de que ela não abre mão é o livro didático. Ressalta sua importância também pelo fato de ser um suporte oferecido a todos os alunos, ao contrário das TIC que "nem todos ainda têm acesso". Tal fato parece ter sido levantado para justificar sua preferência pelo livro didático e não para se opor à questão da democratização do acesso às TIC.

Percebemos que a possibilidade de mudança do discurso de autoridade 
do professor, proporcionada pelo maior domínio dos recursos tecnológicos pelos alunos, não foi considerada pela professora nessa resposta, embora ela tenha valorizado essa oportunidade "de troca" em momento anterior. Por que no momento em que tratamos da relação ensino-aprendizagem, a possível quebra do paradigma do ensino tradicional, que ratifica a palavra de autoridade do professor, é silenciada?

Quando indagamos se a defasagem na formação dos professores quanto à apropriação das TIC no ensino pode comprometer a qualidade do ensino de Ciências, a professora respondeu:

9. "Eu acho que hoje em dia as pessoas elas não podem fugir às TIC. É uma realidade que a gente não pode fugir. Querendo ou não, a gente tem que estar ligada. Agora, realmente eu acho que na medida em que você não usa o que ela pode te dar, você vai ficando pra trás. Então, aquelas pessoas que não usam, resistem a isso, acho que os alunos perdem, os alunos dessas pessoas perdem um pouco".

Marina coloca seu ponto de vista, fazendo um jogo com as expressões 'você/as pessoas' e 'a gente'. Ela utiliza 'você' ou 'as pessoas' quando uso das TIC que está posto e seria imposto aos professores não é aceito (por 'você' ou pelas 'pessoas'). Já 'a gente', serve para mostrar uma posição de aceitação do uso das TIC e para exprimir um juízo de valor, opondo-se àquele professor que não incorpora as TIC na sua prática pedagógica, o que o torna um profissional defasado, comprometendo a qualidade do ensino.

A relação estabelecida na pergunta (formação do professor e apropriação das TIC), aparece no seu enunciado como uma condição de atualização profissional obrigatória da qual não se pode fugir sob a ameaça de se ficar para trás. Ou seja, a professora parece apropriar-se de um discurso de autoridade advindo do paradigma tecnocientíficoinformacional que exclui ou deixa para trás aqueles que não fazem uso das TIC.

Enfatizamos em uma nova pergunta a relação entre o professor que não usa as TIC e a qualidade do seu ensino.

10. "Eu acho que cai é o enriquecimento, é o a mais que o ensino daquela pessoa poderia dar. Às vezes você tem professores excelentes academicamente, que passam o conteúdo muito bem, excelentemente bem".

A professora relativiza a associação entre o uso das TIC e a qualidade do ensino, quando acredita que, se o professor é muito bom academicamente, "passa o conteúdo muito bem" e não utiliza as TIC, a qualidade do seu ensino não é subtraída por isso. Por analogia, entendemos que, quando o professor não é tão bom e não utiliza as TIC, sua prática deixa de ser enriquecida e seu ensino fica subtraído. Nessa afirmativa, podemos inferir que sua concepção de qualidade do ensino restringe-se a "passar bem o conteúdo". As TIC seriam importantes apenas para 
"enriquecer" o conteúdo, contribuindo para a melhoria do ensino tradicional.

Tentando aprofundar, perguntamos se inserção do computador na sala de aula pode ser considerada apenas sinônimo de modernização ou um apelo comercial.

11. "Eu não acho que seja recurso para justificar a mensalidade não. Eu trabalho também numa escola de ponta do RJ, que oferece um serviço de qualidade assim super para os alunos, em termos não só da mídia educativa com 4 ou 5 laboratórios de informática, com aulas dadas na informática, uma das aulas semanais dada na informática, como tem laboratórios onde os alunos têm praticamente microscópios individuais, recursos de laboratório de química individuais e física também. Eu acho que muito mais do que preocupado com a mensalidade que é alta, mas a qualidade do ensino... a proposta é a qualidade do ensino, certamente. Eu acho que os recursos que eles têm são realmente (ênfase) para manter a qualidade do ensino, e a colocação no ranking das escolas do RJ e do Brasil em que ela está. Então ela tem que manter isso, não é só justificar a mensalidade oferecendo isso. [...] Porque principalmente para uma clientela classe A, classe $\mathrm{B}$, às vezes eles têm e trazem tecnologias que a gente já não tem mais lá. Mas é aquela coisa, o nível da clientela exige que aquele serviço seja bem feito. Então, se os pais estão pagando caro, é lógico que eles estão exigindo um serviço de qualidade, e a escola tem que retribuir nesse sentido".

Para responder, ela traz sua prática na escola particular de alto padrão. Ao admitir que os recursos tecnológicos utilizados lá reforçam o padrão de qualidade do ensino, garantindo a posição da escola no ranking das melhores do país, ela concorda categoricamente que nesse colégio as TIC são efetivamente utilizadas por professores e alunos como ferramentas que contribuem para proporcionar aos alunos um padrão de qualidade do ensino compatível com o nível socioeconômico e cultural dos mesmos. Lembrando que a voz do autor é portadora de um ponto de vista que carrega em si juízos de valor, ela apresenta posicionamento diferente daquele relativo ao impacto das TIC na qualidade do ensino da escola pública, quando admitiu que essas ferramentas não são importantes para o professor que passa o conteúdo muito bem.

Quando a professora diz que a clientela da escola privada de alto nível exige um serviço de qualidade, por extensão podemos entender que a inserção das TIC na educação atende às expectativas dessa clientela quanto à eficiência do ensino oferecido. Nesse sentido, essa escola privada, que não pode deixar de ser vista como uma empresa que vende 'serviço de qualidade', tem também, por exigência da clientela, a finalidade de preparar os alunos para disputar as melhores posições profissionais e não apenas um lugar no mercado de trabalho.

\section{DISCUSSÃO E CONCLUSÕES}

Consideramos que a análise microgenética somada à análise backtiniana do discurso permitiu visualizar a intrincada trama de vozes sociais que povoam os enunciados da professora entrevistada. Vozes presentes e ausentes, características 
de uma realidade complexa que se constitui como palco de perspectivas e tensões que problematizam a relação das TIC com a qualidade do ensino de Ciências. No encontro da linguagem social, típica de suas vivências profissionais, com outras linguagens como a discente, a do currículo do colégio, a linguagem acadêmica do campo da Educação em Ciências e outros discursos atrelados às TIC, a análise dessas relações dialógicas levou-nos a compreender os possíveis sentidos atribuídos por Marina à relação entre as TIC e a qualidade da educação, sintetizada abaixo.

No primeiro episódio, Marina declara-se subordinada ao currículo do colégio, aos padrões e às decisões do seu departamento disciplinar. Ela se apropria da palavra de autoridade desses documentos oficiais do colégio, que conformam sua prática pedagógica quando menciona exigir um pouco mais dos alunos. Nesse sentido, o livro didático e as TIC são vistos como ferramentas que potencializam sua concepção de ensino de qualidade.

Os sentidos atribuídos às TIC por Marina nos episódios dois, quatro e cinco não diferem de parte dos resultados encontrados no levantamento de trabalhos acadêmicos em Educação em Ciências, que concebem as TIC como recurso. Essa visão também está explícita no projeto político pedagógico do colégio que concebe a informática "como recurso para aprofundar o aprendizado e [...] para novas estratégias de aprendizagem”. A melhoria da qualidade do ensino é associada à variedade dos recursos utilizados para aumento da motivação, sendo as TIC um desses recursos. Os sentidos atribuídos às TIC são respaldados pela racionalidade técnica típica da linguagem científica, que, associada ao incremento desses aparatos, representa melhoria da qualidade da educação em ciências, reforçando o ensino tradicional e propedêutico.

No terceiro episódio, apesar de declarar-se favorável à utilização desses recursos, Marina os considera como "atividades pequenininhas", comparadas à prova. Em seu discurso Marina reflete a realidade do colégio, que atribui no máximo três pontos às atividades complementares à nota da prova, que vale sete pontos. Nesse sentido, sua voz reflete e refrata a realidade institucional, tomando as normas de avaliação do colégio e o currículo como discursos de autoridade que fazem com que sua prática siga fielmente o significado instituído para essas atividades.

Ao relatar situações em sala de aula em que o aluno 'ensina' à professora a utilizar as TIC, Marina traz a voz dos alunos incorporando-a ao seu enunciado para valorizar a possibilidade de trocar conhecimento com os alunos. A inversão do discurso pedagógico proporcionado pelo domínio dessas ferramentas pelos alunos foi considerado por Marina um aspecto positivo, embora tal posicionamento não pareça trazer consequências inovadoras para suas propostas pedagógicas, se considerada a totalidade de seus enunciados. Consideramos um avanço, do ponto de vista pedagógico, a sua valorização acerca dessa possibilidade, porque potencializaria a concepção do saber compartilhado, amenizando a distância do saber hierarquizado entre professor e aluno. Entretanto, em outro enunciado, quando responde a uma pergunta sobre o processo de ensino-aprendizagem, foi possível deduzir que essa concepção ainda não se materializou em ações pedagógicas efetivas. 
No episódio oito, destacamos dois aspectos nos sentidos que apreendemos de sua voz: o primeiro diz respeito à evolução do conhecimento científico e à possibilidade de atualização imediata das informações proporcionadas pelas TIC, o que permite o acompanhamento dessa evolução como forma de constante atualização profissional. Desse modo, o sentido atribuído às TIC está diretamente associado à qualidade do ensino de Ciências, porque reflete o sentido implícito nos discursos que cercam o enaltecimento das tecnologias como responsáveis pelas mudanças positivas na educação. $\mathrm{O}$ outro aspecto observado, quando Marina enfatiza na entonação empregada ao advérbio "ainda", no episódio "nem todos ainda têm acesso às TIC", ressalta a questão da não democratização do acesso a esses recursos. Embora encontremos nos discursos das políticas educacionais o entendimento das tecnologias no processo educacional como uma forma de democratização do acesso à informação, não se problematiza a questão de que nem todos têm acesso às TIC, e nem tampouco se discutem os modos de acesso.

Nos três últimos episódios, observamos que Marina apropria-se do discurso indireto das "pessoas que não podem fugir às TIC", e inclui sua voz em seguida afirmando que "a gente não pode fugir", reafirmando o pensamento dominante que estabelece estreitas relações da educação com o mundo globalizado, e que tem tido sustentação no poder miraculoso das tecnologias informacionais (MATTELART, 2002). Entretanto, observamos que seu ponto de vista sobre a relação das TIC com a qualidade do ensino é relativizado de acordo com o lugar social a partir do qual seu enunciado é produzido. Como afirma Bakhtin, nossos enunciados refletem e refratam a realidade social, revelando que a questão da tensão presente quando uma voz dialoga com outras está vinculada aos contextos socioculturais. Na escola pública, se o professor é "excelente academicamente, e passa o conteúdo muito bem", e não utiliza as TIC, a qualidade do seu ensino não é subtraída. Já no colégio particular, sua voz modaliza o discurso (“eu acho....”), enfatizando que os recursos "são realmente para manter a qualidade do ensino".

Destacamos como resultado relevante da análise o reconhecimento de acentos avaliativos nas relações de tensão ou nas disputas das vozes que se puseram em contato nos enunciados de Marina. Inicialmente, percebemos que o acesso às TIC não representa propostas pedagógicas inovadoras, mas acentua uma relação utilitarista-instrumental da professora com as TIC, ou seja, do seu uso como uma tecnologia educacional para transmitir o conteúdo. Em relação ao currículo, foi possível depreender da análise que, para cumprir o currículo do colégio tal como é imposto, a professora prescinde das TIC e talvez por isso ela não as utiliza em sua prática.

Embora ela veja uma relação particular entre o uso das TIC e a ciência, fica claro que essa relação diz respeito apenas à velocidade do avanço dos conhecimentos científicos, restando ao ensino de ciências oferecer acesso, pelos meios eletrônicos, à divulgação do "que está acontecendo na hora". Assim, o papel da escola, para a entrevistada, é o de permitir o acesso às TIC para que os jovens possam acompanhar as mudanças científicas e tecnológicas ocorridas na 
sociedade, para não tornar o ensino tão defasado da realidade dos alunos e das exigências da contemporaneidade.

Concluindo, consideramos que olhar minuciosamente para os ecos dialógicos embutidos no discurso de Marina sobre sua prática pedagógica permitiu-nos compreender os sentidos atribuídos por ela à relação entre as TIC e a qualidade da educação em Ciências, assim como compreender que essa relação é conformada, em seu discurso, pelas diferentes realidades educacionais em que as TIC são inseridas.

\section{NOTA}

${ }^{1}$ Para Van Dijk (2004), o episódio seria uma unidade de análise de discurso em um nível intermediário entre a unidade-oração e a unidade-texto, discurso ou conversação. Isto quer dizer que o episódio selecionado pode tanto corresponder a uma unidade sintática como uma oração, por exemplo, como a um trecho qualquer do discurso que não corresponda a uma unidade formal.

\section{REFERÊNCIAS}

ANDRÉ, M. Estudos de caso revelam efeitos sócio-pedagógicos de um programa de formação de professores. Revista Lusófona de Educação. N. 6, Lisboa, Portugal, 2005, pp. 93-115.

BAKHTIN, M. Estética da Criação Verbal. São Paulo: Martins Fontes, 2003.

BAKHTIN, M. Marxismo e filosofia da linguagem. São Paulo: Hucitec, 2004.

BAKHTIN, M. The Dialogic Imagination. Edited by Michael Holquist. Austin: University of Texas Press, 1984. BARRETO, R. G. Discursos, Tecnologias, Educação. Rio de Janeiro: EdUERJ (Série Pesquisa em Educação, Práticas de Linguagem), 2009, 188p.

BRAIT, B. Bakbtin, dialogismo e construção do sentido. Org. Beth Brait. $2^{\mathrm{a}}$ ed. Campinas, SP: Unicamp, 2005. BRASIL. Importância dos recursos tecnológicos na educação In: Parâmetros curriculares nacionais: terceiro e quarto ciclos do ensino fundamental: introdução aos parâmetros curriculares nacionais / Secretaria de Educação Fundamental. Brasília: MEC/SEF, 1998.

BRASIL. Plano de Desenvolvimento da Educação. Razões, princípios e programas.Ministério da Educação. Disponível em: http://portal.mec.gov.br/arquivos/livro/index.htm, 2007.

FELINTO, E. A Religião das máquinas: ensaios sobre o imaginário da cibercultura. Porto Alegre: Sulina, 2005.

GIORDAN, M. O computador na educação em ciências: breve revisão crítica de algumas formas de utilização. Ciência \& Educação, v. 11, n. 2, 2005, pp. 279-304.

MATTELART, A. História da Sociedade da Informação. Tradução: Nicolas N. Campanário. São Paulo: Edições Loyola, 2006.

MOREIRA, A.F.B. e KRAMER, S. Contemporaneidade, educação e tecnologia. Educação e Sociedade, v. 28, n.100 - Especial, 2007, pp. 1037-1057.

ORLANDI, E. P. Análise do discurso: princípios e procedimentos. São Paulo: Pontes, 2009.

PRETTO, N. Linguagens e tecnologias na educação. In: Candau, V.M. (Org) Cultura, linguagens e subjetividade no ensinar e aprender. Rio de Janeiro: DP\&A, $2^{\mathrm{a}}$ edição, 2001, pp. 135 -160.

REZENDE F.; DUARTE, M.; SCHWARTZ, L. B.; CARVALHO, R. C. de. Qualidade da Educação na voz dos professores. Ciência \& Educação, v. 17, n. 2, 2011, pp. 269-288.

SAVIANI, D. Escola e Democracia. São Paulo: Cortez, 1984.

SERRA, G. M. D. e ARROIO, A. Análise dos trabalhos apresentados nos ENPECs no período de 1997 a 2005, onde é abordado na temática desenvolvida o uso do microcomputador como recurso para aprendizagem. In: Anais do VI ENPEC - Encontro Nacional de Pesquisa em Educação em Ciências, Florianópolis - SC, 2007. 
SILVA, L. H. A.; SCHNETZLER, R. P. O discurso pedagógico de um professor a elaboração de conhecimentos científicos. Ensaio - Pesquisa em Educação em Ciências, Vol 11, N. 1, junho, 2009, pp. 55-70. TONIATO, J.D.; FERREIRA, L.B.; FERRACIOLI, L. Tecnologia no Ensino de Física: Uma Revisão do. XVI Simpósio Nacional de Ensino De Física. In: X Encontro de Pesquisa em Ensino de Física, Londrina-PR, 2006.

VAN DIJK, Teun A. Cognição, discurso e interação. 6. ed. São Paulo: Contexto, 2004.

VOLOSHINOV, V.N. Discourse in life and discourse in art - concerning sociological poetics. Tradução de Carlos Alberto Faraco e Cristovão Tezza. In: VOLOSHINOV, Freudism, New York. Academic Press, 1976.

WERTSCH, J.V. Voces de la mente: um enfoque sociocultural para el estúdio de la acción mediada. Traducción: Adriana Silvestri - Madrid: Visor Distribuciones S.A, 1993.

Data de Recebimento: 06/10/2011

Data de Aprovação: 10/10/2011

Data da Versão Final: 27/10/2011 
